\title{
Crane technique with the vacuum bell device for improving access in the Nuss procedure
}

\author{
Hany Elsayed, FRCS Cth, Cairo, Egypt
}

From the Thoracic Surgery Department, Ain Shams University, Cairo, Egypt.

Disclosures: Author has nothing to disclose with regard to commercial support.

Received for publication Feb 3, 2015; revisions received Feb 12, 2015; accepted for publication March 26, 2015; available ahead of print May 1, 2015.

Address for reprints: Hany Elsayed, FRCS Cth, Thoracic Surgery Department, Ain Shams University, Cairo, Egypt (E-mail: Drhany.elsayed@yahoo.co.uk).

J Thorac Cardiovasc Surg 2015;150:1372-3

$0022-5223 / \$ 36.00$

Copyright (c) 2015 by The American Association for Thoracic Surgery

http://dx.doi.org/10.1016/j.jtcvs.2015.03.064

The Nuss procedure is one of the most common procedures performed in the treatment of pectus excavatum. Even though the procedure is associated with a higher risk of cardiac injury and the need for insertion of a metal bar, its improved cosmetic result and avoidance of the need for cartilage resection make it a preferable surgical option to the modified Ravitch approach for many surgeons.

Although the technique is considered minimally invasive relative to the modified Ravitch procedure, the Nuss procedure requires the creation of a substernal tunnel for proper bar positioning. The advancement of the metal introducer between the retracted sternum and the heart is a maneuver that can be hazardous. In a few cases described in the medical literature, the catastrophic complication of cardiac injury has occurred during the Nuss procedure. ${ }^{2}$

I propose a simple, novel method of improving access to the anterior mediastinum for our cases of the Nuss procedure by using the vacuum bell device. This improved access depends on the principle of the crane technique (lifting the sternum), which was initially described by Park and colleagues $^{3}$ as a safety measure during the Nuss procedure for pectus excavatum. My hypothesis was that the technique would improve the surgical field access without the need for an additional incision in the sternum in a procedure that can be done for cosmetic purposes in a wide range of patients with pectus excavatum.

\section{SURGICAL TECHNIQUE}

In a consecutive series of 9 patients, 7 male and 2 female patients with a median age of 16 years (range, 9-31 years), I performed this modified crane technique with the vacuum bell device during the Nuss procedure for treating patients with pectus excavatum.

A thoracic epidural catheter was inserted for analgesia. A double-lumen endotracheal tube was inserted, and singlelung ventilation was achieved. After complete preparation of the surgical field, a sterile, reusable vacuum bell device was placed on the patient's sternum (Figure 1). Appropriate sizing for each chest size and sex was measured according

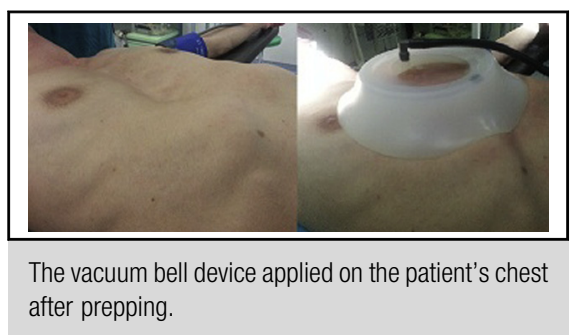

Central Message

We propose a simple, novel method of improving access to the anterior mediastinum for cases of the Nuss procedure by using the vacuum bell device.

See Editorial Commentary page 1374.

to the recommendation by the device's inventor, Ekart Klobe. ${ }^{4}$ Negative suction was applied until the skin covered the surface of the transparent plastic part of the vacuum bell.

I proceeded with 2 lateral incisions and a right-sided 5$\mathrm{mm}$ incision for the camera port just superior to the lateral incision. No carbon dioxide insufflation was used. I allowed 60 minutes before deflation of the pressure on the vacuum bell to avoid a subcutaneous hematoma. A 5-minute deflation period was used. Reinflation of the device was performed, with deflation every 60 minutes for 5 minutes if needed. The rest of the routine Nuss procedure steps were performed; these included advancement of the metal bar introducer, attachment of a nylon tape, passage of a correctly sized Nuss bar, flipping of the bar, fixation with a single stabilizer, and closure without insertion of a chest drain (if appropriate).

\section{RESULTS}

With the introduction of this modified technique, I observed the following:

1. The visualization of the tip of the metal introducer was improved, minimizing the blind spot area.

2. The narrow retrosternal anterior mediastinum was expanded by pulling up the sternum as the vacuum bell device was being inflated.

3. The rubbing of the metal introducer against the pericardium was less.

4. The hematoma formation of the skin over the sternum was avoided by a pause in the device inflation every 60 minutes. 


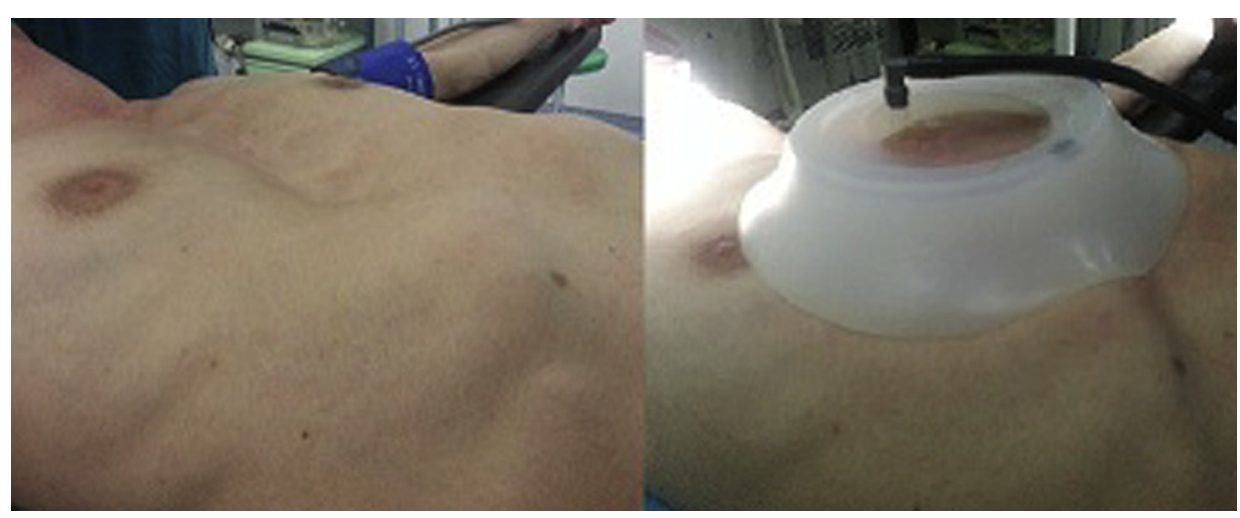

FIGURE 1. The vacuum bell applied on the patient's chest after surgical preparation.

The main result is that in my series of patients I developed an easy and safe Nuss procedure, with the surgeons at my institution feeling comfortable with this modification.

\section{DISCUSSION}

The crane technique was originally described as a sternal lifting method with a sternal wire and a metallic lifting device. It allows the depressed sternum in patients with pectus excavatum to move away from the heart, thus allowing a safer insertion of the bar in the Nuss procedure. ${ }^{5}$ Similar benefit can be achieved by using the vacuum bell device, which was invented to suck the sternum outward negatively as a nonsurgical procedure for patients with pectus excavatum. The vacuum bell device used in this series of patients was developed by a German engineer who himself had pectus excavatum. ${ }^{4}$

Complications and relevant side effects of the device include subcutaneous hematoma and transient paresthesia of the upper extremities during the application, as well as rib fractures in rare cases. ${ }^{4} \mathrm{I}$ therefore allow a 5-minute break for every 60 minutes of application of the vacuum bell during the Nuss procedure to avoid a subcutaneous hematoma or a nerve injury.

I believe that this new technique uses the simplicity of the vacuum bell device to avoid sutures in the sternum, improve surgical access, reduce the chance of cardiac injury by improving visualization of the blind spot, and potentially avoid the hazardous use of intrathoracic carbon dioxide insufflation. It is a routine now to use this procedure in my institution for all patients when performing the Nuss procedure for pectus excavatum.

\section{References}

1. Croitoru DP, Kelly RE Jr, Goretsky MJ, Lawson ML, Swoveland B, Nuss D. Experience and modification update for the minimally invasive Nuss technique for pectus excavatum repair in 303 patients. J Pediatr Surg. 2002;37:437-45.

2. Gips H, Zaitsev K, Hiss J. Cardiac perforation by a pectus bar after surgical correction of pectus excavatum: case report and review of the literature. Pediatr Surg Int. 2008;24:617-20.

3. Park HJ, Jeong JY, Jo WM, Shin JS, Lee IS, Kim KT, et al. Minimally invasive repair of pectus excavatum: a novel morphology-tailored, patient-specific approach. J Thorac Cardiovasc Surg. 2010;139:379-86.

4. Klobe E. Trichterbrust und Saugglocken gegen Trichterbrust. Available at: http:// www.trichterbrust.de. Accessed April 28, 2014

5. Yoon YS, Kim HK, Choi YS, Kim K, Shim YM, Kim J. A modified Nuss procedure for late adolescent and adult pectus excavatum. World J Surg. 2010;34: 1475-80. 